\title{
MORBIDLY ADHERENT PLACENTA: MANAGEMENT OPTIONS
}

\author{
ABIDA SAJID ${ }^{1}$, AQSAM SAJID $^{2}$, ARHAM SAJID $^{1}$, MAHAM ABID $^{3}$ \\ ${ }^{1}$ Department of Obstetrics \& Gynaecology, King Edward Medical University, Lahore, \\ ${ }_{2}^{2}$ MBBS student, Shaikh Khalifa Bin Zayed Al-Nahyan Medical and Dental College, Lahore, \\ ${ }^{3}$ Department of Radiology, Shaukat Khanum Memorial Cancer Hospital
}

\begin{abstract}
Background: Placenta previa with placenta accreta spectrum is one of the most feared disorders responsible for increase morbidity and mortality in obstetric patients. This study aims to reduce maternal morbidity and mortality by detecting risk factors, performing required investigations, and doing appropriate management options timely.

Objectives: To reduce maternal morbidity and mortality by detecting risk factors, performing required investigation, and deciding appropriate management options.

Methods: The study is a descriptive case series design, carried out on 72 patients of Morbidly adherent placenta (MAP) of a tertiary care hospital, in 6-years duration from $15^{\text {th }}$ January 2015 till $15^{\text {th }}$ January 2021 . Patients of OPD and the emergency department were diagnosed for MAP by using grayscale ultrasounds, color Doppler USG's (in most cases), and MRI's (in only a few cases). Different management options were studied, and maternal morbidities were observed. In most cases, patients had operative deliveries with planned/ emergency hysterectomies, except for some having conservative surgery.

Results: In the period of 6 years, the total number of deliveries was 35940. Among these, 22140 were spontaneous vaginal deliveries and 13800 were C-sections. The incidence of MAP was 1 per 499 normal deliveries and 1 per 192 in C-sections. The criterion for MAP was fulfilled by 72 patients. MAP diagnosed in the antenatal period was $43 \%$ while $57 \%$ were diagnosed in an emergency. Most patients had a history of C-sections and many underwent emergency obstetric hysterectomies. Blood transfusions were given to all patients in our study. Only 4(5.5\%) patients expired in our study.

Conclusion: Antenatal diagnosis of morbidly adherent placenta, followed by a planned surgical management, without separating the placental and early recourse to caesarean hysterectomy ultimately gives good results.
\end{abstract}

Keywords: Adherent Placenta, Morbidity, Massive Obstetric Hemorrhage, Obstetric Hysterectomy.

How to cite this article: Sajid A, Sajid A, Sajid A, Abid M. Morbidly adherent placenta: management options. Pak Postgrad Med J 2020;31(1): 3-7

This is an Open Access article distributed under the terms of the Creative Commons Attribution License (http://creativecommons.org/licenses/by/3.0), which permits unrestricted use, distribution, and reproduction in any medium, provided the original work is properly cited. DOI: HTTPS//DOI.ORG/10.51642/ppmj.v31i01.375

Correspondence to: Abida Sajid, Associate Professor, Department of Obstetrics \& Gynaecology, Unit-V, King Edward Medical University, Lahore, Pakistan.

Email: drsajidrafi@gmail.com

\section{INTRODUCTION}

Morbidly adherent placenta now renamed as placenta accreta spectrum with its variants is one of the most feared catastrophes, responsible for increase maternal morbidity and mortality in obstetrics. Known consequences of the morbidly adherent placenta are increasing need for obstetric hysterectomy, multiple blood transfusions, injury to the bowel or urinary bladder, admission in ICU, prolonged anesthesia, and prolong stay in hospital. Antenatal diagnosis allows arranging delivery at the hospital settings where adequate resources and expertise available with a reduction in maternal morbidity..$^{1,2,3}$

The rate of occurrence of the morbidly adherent placenta is increasing side by side with the increasing caesarean section rate. Its incidence skyrocketed over the last 4 decades. In the 1970's it was roughly 1 in every 4027 pregnancies, in the 1980's it was 1 in every 2510 pregnancies and from 1982 to 2002 it was 1 in every 533 pregnancies. A study in 2016 carried out in the United States was 1 per 272 for ladies who had a delivery-related hospital discharged diagnosis, when compared with other studies published is much high. ${ }^{4}$ 
There are 3 types of this condition:

Accreta: Placenta attached to the myometrium (75\% of cases)

Increta: Placenta extends into the myometrium: (17\% of cases

Percreta: Placenta extends to the entire myometrium and uterine serosa: ( $7 \%$ of cases)

Statistically, $75 \%$ of women with placenta previa and prior caesarean section have morbidly adherent placenta. A Morbidly adherent Placenta may lead to excessive obstetric hemorrhage, disseminated intravascular coagulation (DIC), emergency hysterectomy, and extensive surgery for uterine and internal iliac arteries ligation, urological injuries, multiple blood transfusions, renal failure, or even death (10\% cases).

\section{Ultrasound Features of Placenta Accreta:}

Placenta Accreta can occur early in the first trimester and includes:

- Lower uterine implantation

- Many blood vessels

- Loss of normal hypo-echoic retro-placental zone

- Abnormal interphase of the uterine serosa-bladder

- Ultrasound has high sensitivity and diagnostic accuracy $(80-93 \%)$

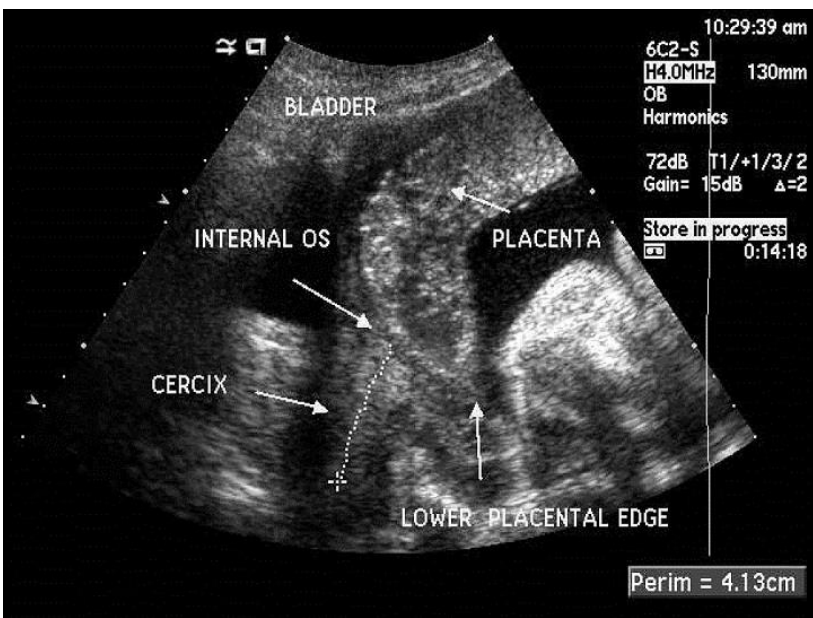

Fig 1: Ultrasound showing Placenta Previa Accreta

Management: For the successful management of placenta Acreta, high risk women must be recognized, on the basis of clinical factors, as soon as possible. A high index of suspicion will be kept in women with placenta previa with a previous one or more than one caesarean section. Detailed maternal counseling along with thorough planning at the time of delivery is required. A multidisciplinary approach, by assuring that the most skilled team, is available for these patients. Availability of an ample amount of fresh blood and blood products (packed cells, platelets, FFP's, and cryoprecipitate) is a mandatory prerequisite.

Diagnostic imaging techniques involve grayscale ultrasound, color Doppler ultrasound, and magnetic resonance imaging.

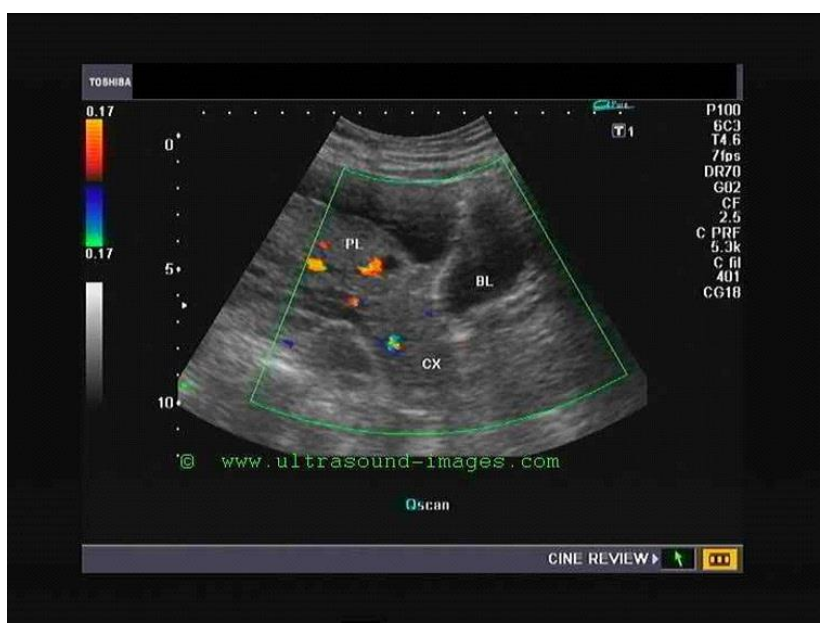

Fig 2: Color Doppler showing MAP

\section{METHODS}

Study Design: Descriptive Case Series. It was conducted in the Gynae and Obstetrics, Unit-5, KEMU Lahore, from $15^{\text {th }}$ January 2015 to $15^{\text {th }}$ January 2021 . Those patients were included in the study that had the following features. The suspicion of morbidly adherent placenta was kept for all patients in the high-risk group including:

- Placenta previa with H/O Previous C-section

- Placenta lying under the scar of the LSCS

- History of excessive curettage or uterine surgery like myomectomy

- Postpartum infection.

- All those with normally situated placenta delivering vaginally are excluded from the study.

Management Options: All patients underwent following surgical management:

- LSCS and caesarean hysterectomy

- Repair and resection of a segment of uterus with focal morbidly adherent placenta

- Trial Hemostasis with bilateral uterine artery ligation and internal iliac artery ligation and brace sutures.

\section{RESULTS}

In the period of 6 years, the sum total number of deliveries was 35940. Among these, 22140 were spontaneous vaginal deliveries and 13800 were Csections. The incidence of MAP was 1 per 499 normal deliveries and 1 per 192 in C-sections. The criteria for MAP was fulfilled by 72 patients. MAP diagnosed in the antenatal period was $43 \%$ while $57 \%$ were diagnosed in 
an emergency. The majority of patients had a history of C-sections, 61 underwent emergency obstetric hysterectomies and 11 had conservative surgeries performed. Blood transfusions were given to all patients in our study. Only 4(5.5\%) patients died in our study.

Table 1: Demographic Features

\begin{tabular}{lcc}
\hline Age & Frequency & Mean \pm S.D. \\
\hline Maternal Age & 24-38 years & $31 \pm 3.20$ \\
Gravidity & 2-6 & $4.00 \pm 1.15$ \\
Duration of & 34-37 weeks & $35.5 \pm 0.53$ \\
pregnancy & & \\
\hline
\end{tabular}

Table 2: Diagnosis of MAP

\begin{tabular}{llc}
\hline Total cases & 72 & $100 \%$ \\
\hline Antenatal Diagnosed & 31 & $43 \%$ \\
Received in Emergency & 41 & $57 \%$ \\
\hline
\end{tabular}

Table 3: Estimated Blood loss and Frequency of Blood Transfusion

\begin{tabular}{lll}
\hline Groups & $\begin{array}{l}\text { Estimated } \\
\text { Blood Loss } \\
(\mathrm{ml})\end{array}$ & $\begin{array}{l}\text { Blood } \\
\text { Transfusion } \\
\text { Units }\end{array}$ \\
$\begin{array}{l}\text { Caesarean } \\
\text { Hysterectomy-53 }\end{array}$ & -6 Units \\
$\begin{array}{l}\text { Sub-total Caesarean } \\
\text { Hysterectomy-8 }\end{array}$ & $2000-2500$ & $4-8$ Units \\
$\begin{array}{l}\text { Trial Hemostasis \& } \\
\text { Conservation of } \\
\begin{array}{l}\text { Uterus by segment } \\
\text { resection-11 }\end{array}\end{array}$ & $2300-3000$ & $8-10$ Units \\
\hline
\end{tabular}

Table 4: Morbidity of Placenta Previa Accreta

\begin{tabular}{lcc}
\hline $\begin{array}{l}\text { Intra Operative and Post- } \\
\text { Operative Complications: }\end{array}$ & & \\
\hline $\begin{array}{l}\text { Need for Internal Iliac Artery } \\
\text { Ligation. }\end{array}$ & 10 & $13.8 \%$ \\
Urinary Bladder Injury & 8 & $11.1 \%$ \\
Need for Re- open/ Re- & 5 & $6.9 \%$ \\
Laparotomy & & \\
Recurrent Hemorrhage & 6 & $8.3 \%$ \\
Admission to ICU & 25 & $34.7 \%$ \\
Pyrexia/Fever & 12 & $16.6 \%$ \\
Prolonged urinary bladder & 14 & $19.4 \%$ \\
Catheterization & & \\
Prolonged Hospitalization & 28 & $38.4 \%$ \\
Death & 4 & $5.5 \%$ \\
\hline
\end{tabular}

\section{DISCUSSION}

The overall incidence of placenta previa with morbid adherence (placenta accreta) is increasing with the rise in caesarean section rate. Various studies have observed that incidence of MAP has increased over the last three decades. Before embarking on surgery for suspected placenta accreta spectrum, all resources with multidisciplinary team should be in place for the successful management of these high-risk patients. Its incidence in our study was found 1 in 192; while a search of the literature showed that it was 1 in 533 in the USA. The reason for the higher rate in our study was that our hospital is a tertiary care referral hospital ${ }^{[3,8]}$. The rising rate and trend of placenta accreta over the past four decades are likely due to a change in risk factors particularly the increased rate of cesarean delivery. The incidence of placenta accreta is $3 \%$ with the previous one c-section, $11 \%$ with the previous two, $40 \%$ with the previous three, $61 \%$ with four, and $67 \%$ with the previous five c-section ${ }^{[4,5,10]}$.

risk of placenta accreta and likewise placenta previa increased with the number of previous caesarean section deliveries ${ }^{[3,11]}$. Placenta previa with morbid adherence and previous caesarean section was the main reason in $61(84.7 \%)$ of cases in our study which is comparable to Sujata Sharma et al. ${ }^{[8]}$. In a study by Clark et al. an increased in occurrence of placenta previa after caesarean section from $0.26 \%$ women with an unscarred uterus to $0.65 \%$ after one and up to $10 \%$ after four or more caesarean sections ${ }^{[4,5,6,7]}$. Few studies reported the risk of placenta accreta increased up to $39 \%$ after two caesarean sections. Majority of patients in our study had previous two and three c-sections. Desai et al. reported similar findings ${ }^{8}$. Focus on reducing the primary csection must be given to reduce the incidence of MAP and morbidity related with it.

The suspicion of MAP will be kept in mind in pregnant women presented with vaginal bleeding after 20 weeks of gestation. The diagnosis of MAP in this study was made by grayscale ultrasound and color Doppler ultrasound in most of the patients but MRI is a gold standard investigation and used to complement the ultrasound. Four patients of MAP out of 72 were diagnosed with MRI, available at Radiology department of Mayo hospital KEMU Lahore ${ }^{[6,11,12,13,14]}$. According to RCOG green-top guideline 2018 (27a), a pregnant woman with a history of previous caesarean section and an anteriorly located placenta in the lower segment of uterus at the routine fetal anomaly scan should be specifically screened for placenta accreta spectrum ${ }^{14}$. These women must be managed at tertiary care hospitals by early diagnosis and early referral to bring down the maternal morbidity and mortality ${ }^{14}$. In our study, diagnosed cases of placenta accreta spectrum were $43 \%$ (31) in the antenatal period while $57 \%$ (41) were received in an emergency. This was due to the unbooked status and undiagnosed patients in the antenatal period referred to 
our hospital in an emergency from catchment areas. Awareness will be created among GPs, LHVs and Midwifes to anticipate this condition and early referral.

Maternal morbidity with placenta accreta is associated with a massive obstetric hemorrhage, an increased need for emergency hysterectomy, and multiple blood transfusions, prolong anesthesia, urological injuries, admission to ICU and prolong hospital stay, DIC, and maternal death. In our study MAP lead to emergency hysterectomy in $61(84.72 \%)$ patients, conservative surgery done in 11(15.28\%), need for massive blood transfusion $(90 \%)$, urological injuries $(11.1 \%)$, ICU admissions (34.2\%), and prolong hospital stay (38.8\%). Similar results were found by Memon E and et al [10]. Another study reported comparative findings but their sample size was small ${ }^{[24]}$. Su HW in Taiwan had less successful results with conservative management of abnormally invasive placenta to save the uterus and had more morbidity ${ }^{[16]}$.

Maternal mortality in our study was 4(5.5\%). These findings were similar to the study in India ${ }^{[8]}$ and in a local study maternal mortality was high up to $17.4 \%{ }^{[10]}$ and some studies reported maternal mortality of $20 \%{ }^{[8,16,21]}$. The less case fatality rate in our study was found because of a multidisciplinary team approach in diagnosed cases as well as those encountered intraoperatively as emergency cover available from our surgical department. We had involved a senior obstetrician, surgeon, urologist, hematologist, senior anesthetist, with a backup supply of blood and blood product. We proceeded to Obstetric hysterectomy straight forward without separating the placenta to reduce the blood loss, contrary to the study of Su HW in Taiwan who had observed more morbidity with a uterine conservative approach ${ }^{[16]}$. Our study required an internal iliac artery Ligation of 10(13.8\%) cases. Trial haemostasis was carried out in $11(15 \%)$ cases to conserve the uterus by ligation of uterine and internal iliac arteries. We had more blood loss in cases of anteriorly located placenta Accreta when we attempted to

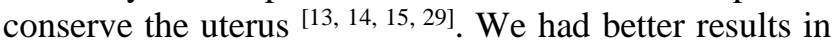
case of non-separation of the placenta and early decision to proceed for hysterectomy requiring less blood transfusion and less maternal morbidity. Robinson et al. suggested that there is a higher benefit of planned hysterectomy verses emergency obstetric hysterectomy $[25,28]$.

We recommend this strategy to reduce maternal complications. We further recommend the early diagnosis and timely referral for booking at tertiary care hospital so that these patients will be managed in a better way with a multidisciplinary care team.

\section{CONCLUSIONS}

Antenatal diagnosis of morbidly adherent placenta, followed by a planned surgical management, without separating the placental and early recourse to caesarean hysterectomy ultimately gives good results.

\section{Conflict of interest: none Source of funding: none}

\section{ETHICAL APPROVAL}

The study was approved by the Institutional Review Board of King Edward Medical University, Lahore, Pakistan. Vide reference No. 29/RC/KEMU dated January 14, 2021.

\section{REFERENCES}

1. Daskalakis G, Anastasakis E, Papantoniou N, Mesogitis S, Theodora M, Antsaklis Emergency obstetric hysterectomy. Acta Obstet Gynecol Scand 2007; 86: 223-227.

2. Perez-Delboy A,Wright JD. Surgical management of placenta accreta; to leave or remove the placenta: BJOG 2014; 121:163-170.

3. Mazouni C, Gorincour G, Juhan V, Bretelle F. Placenta accreta: a review of current advances in prenatal diagnosis. Placenta 2007; 28: 599-603.

4. Miller DA, Chollet JA, Goodwin TM. Clinical risk factors for placenta previa-placenta accreta. Am J Obstet Gynecol 1997; 177: 210-214.

5. Clark SL, Koonings PP, Phelan JP. Placenta previa/accreta and prior caesarean section. Obstet Gynecol 1985; 66: 89-92.

6. Esakoff TF, Sparks TN, Kaimal AJ, Kim LH, Feldstein VA, Goldstein RB, et al. Diagnosis and morbidity of placenta accreta. Ultrasound Obstet Gynecol 2011; 37: 324-327.

7. Gielchinsky Y, Rojansky N, Faso uliotis SJ, Ezra Y. Placenta accreta-summary of 10 years: a survey of 310 cases. Placenta2002; 23: 210-214.

8. Sujata Sharma, Upasana, Anita Madan, Amarjeet Kaur. (2017) Morbidly Adherent Placenta: management and maternal outcome. Inter. J.Curr. Res. Med. Sci. 2017,3(7):45-51.

9. Desai $\mathrm{R}$ et al. Morbidly adherent placenta and its maternal and fetal outcome. Inter J Reprod Contrcept Obstet Gynaecol 2017 May, 6(5): 18901893.www.ijrcog org.2017.

10. Memon E, Ashfaq S, Naqvi KZ, Sultan S, Iqbal F, Aziz S, Irfan SM. Maternal outcome in Morbidly Adherent Placenta in Obstetric patients. J Soc Obstet Gynaecol Pak.2017; vol 7(2):85-88

11. Hamisa M, Mashaly E, Fathy S.Tawfeek A.Role of Doppler US and MRI in the diagnosis of placenta accreta. Alexandria J Medic. 2015;51: 225-30 
12. Warshak $\mathrm{CR}$, Eskander R, Hull AD, Scioscia AL, Mattrey RF, Benirschke K, Resnik R. Accuracy of ultrasonography and magnetic resonance imaging in the diagnosis of placenta accreta. Obstet Gynecol 2006; 108: 573-581.

13. Jing LE, Wei G, Mengfan S, Yanyan H. Effect of site of placentation on prengnancy outcomes in patients with placenta previa PLoS ONE 2018;13(7):e0200252

14. Royal College of Obstetrician \& Gynaecologist. Green Top Guideline No. 27a September 2018.

15. Wo S Kocherginsky, Hibbard JU: Abnormal placentation: twenty- year- analysis. American Journal Obstetetric Gynaecolgy 2005; 192:1458-61.

16. Su HW Yi YC Tseng JJ, Chen WC Chen Y. Maternal outcome after conservative management of abnormal invasive placenta; Tiawan J of Obstet Gynaecol, 2017 June, 56(3)353-357.

17. Shih JC, Palacios Jaraquemada JM, Su YN, Shyu MK, Lin $\mathrm{CH}$, Lin SY, et al. Role of three-dimensional power Doppler in the antenatal diagnosis of placenta accreta: comparison with gray-scale and color Doppler techniques. Ultrasound Obstet Gynecol 2009; 33: 193-203.

18. Jing LE, Wei G, Mengfan S, Yanyan H. Effect of site of placentation on prengnancy outcomes in patients with placenta previa PLoS ONE 2018;13(7): e0200252.

19. Lerner JP, Deane S, Timor-Tritsch IE. Characterization of placenta accreta using transvaginal sonography and color Doppler imaging. Ultrasound Obstet Gynecol 1995; 5: 198-201.

20. Comstock $\mathrm{CH}$. The antenatal diagnosis of placental attachment disorders. Curr Opin Obstet Gynecol 2011; 23: 117-122.

21. Mazhar B, Batool M, Batool A. Post-partum hemorrhageand its predisposing factors In WHO Multi-CountrySurvey on Maternal and Newborn Health, Pakistan. J Soc Obstet Gynaecol Pak. 2018;8(2):104-108.

22. Wong HS, Cheung YK, Williams E. Antenatal ultrasound assessment of placental/myometrial involvement in morbidly adherent placenta. Aust $\mathrm{N}$ Z J Obstet Gynaecol 2012; 52: 67-72.
23. Ulman-Wlodarz I, Nowosielski K, Poreba R, Poreba A. Placenta previa increta with caesarean section scar invasion. Int J Obstet Gynecol 2009; 107 S2: S413S729; XIX World Congress of Gynecology and Obstetrics, Cape Town, 2009.

24. Anjum F, Bashir R, Rahim A. Maternal and Foetal Outcome in case of Placenta Previa, Accreta and inccerta. Ann King Edward Med Coll 2016; 22(4): 29630010.doi 21649/akemu.v22i4.1469

25. Robinson BK, Grobman WA. Effectiveness of timing strategies for delivery of individuals with placenta previa and accreta. Obstet Gynecol 2010; 116: 835-842.

26. Al-Serehi A, Mhoyan A, Brown M, Benirschke K, Hull A, Pretorius DH. Placenta accreta: an association with fibroids and Asherman syndrome. J Ultrasound Med 2008; 27: 1623-1628.

27. Hamar BD, Wolff EF, Kodaman PH, Marcovici I. Premature rupture of membranes, placenta increta, and hysterectomy in a pregnancy following endometrial ablation. J Perinatol 2006; 26: 135-137.

28. Eller AS, Porter TF, Soisson P, Silver RM. Optimal management strategies for placenta accreta $\mathrm{Br} \mathrm{J}$ Obstet Gynecol: 2019;115:648-54.

29. Chou MM, Chen WC, Tseng JJ, Chen YF, Yeh TT, Ho ES. Prenatal detection of bladder wall involvement in invasive placentation with sequential two-dimensional and adjunctive three-dimensional ultrasonography. Taiwan J Obstet Gynecol 2009; 48: 38-45.

30. Royal College of Obstetricians and Gynaecologists. Placenta praevia, placenta praevia accreta and vasa praevia: diagnosis and management. Green-top Guideline No. 27, January 2011, RCOG: London, UK.

\section{AUTHORS' CONTRIBUTION:}

ABIDA S: Manuscript Writing, Data Collection, Research Methodology

AQSAM S, ARHAM S: Data Collection

MAHAM A: Statistical Analysis, Research

Methodology 